\title{
Image denoising with two-dimensional zero attracting LMS algorithm
}

\section{2 boyutlu sıfıra çeken LMS algoritmasıyla görüntü iyileştirme}

\author{
Gülden ELEYAN ${ }^{+}$(D), Muhammed SALMAN ${ }^{2}$ iD
}

\begin{abstract}
1Electrical and Electronics Engineering Department, Engineering \& Architecture Faculty, Avrasya University, Trabzon, Turkey. ${ }^{2}$ College of Engineering and Technology, American University of the Middle East, Egaila, Kuwait. gulden.eleyan@avrasya.edu.tr, mohammadsalman@aum.edu.kw
\end{abstract}

Received/Geliş Tarihi: 25.01.2018, Accepted/Kabul Tarihi: 29.11.2018

doi: $10.5505 /$ pajes.2018.06982

* Corresponding author/Yazıșilan Yazar Research Article/Araștırma Makalesi

\begin{abstract}
In this paper, we propose a new two-dimensional (2D) zero-attracting least-mean-square (ZALMS) adaptive filter by imposing a sparsity aware $l_{1}$-norm penalty term into the cost function of the $2 D$-LMS algorithm. Comparisons with 2D-LMS and BM3D algorithms were conducted both on sparse and non-sparse images. The carried-out simulations show that the proposed algorithm has good capabilities in updating the filter coefficients along both horizontal and vertical directions, and its performance is similar with the 2D-LMS algorithm with lower computation time. But 2D-ZALMS performs better than BM3D algorithm.
\end{abstract}

Keywords: LMS, Image restoration, Sparse signals
Öz

Bu yazıda, iki boyutlu en küçük kare algoritmasının (2D-LMS) maliyet fonksiyonuna seyrekliği farkeden $l_{1}$-norm ceza terimi yükleyen yeni bir $2 D$ sıfira çeken en küçük ortalama kare (ZALMS) uyarlamalı filtreyi önermekteyiz. 2D-LMS ve BM3D algoritmaları ile karșllaștırmalar hem seyrek hem de seyrek olmayan görüntülerde yürütülmüştür. Simülasyon sonuçlarl, önerilen algoritmanın hem yatay hem de dikey doğrultuda filtre katsayılarının güncellenmesinde iyi yeteneklere sahip olduğunu göstermiştir ve performansı düşük hesaplama zamanına sahip 2D-LMS algoritması ile aynı/daha iyidir. Ancak 2D-ZALMS, BM3D algoritmasından daha iyi performans göstermektedir.

Anahtar kelimeler: LMS, Görüntü iyileștirme, Seyrek sinyaller

\section{Introduction}

The earliest studies on gradient-based adaptive algorithms may be traced back to more than six decades. In 1950, the leastmean-square (LMS) algorithm was discovered by Widrow and Hoff [1] in their investigation of the adaptive linear element machine. It is a stochastic gradient algorithm in that it iterates each tap weight of the filter [2]. Adaptive filters are widely used in many applications including system identification, echo cancellation [3], channel equalization, etc.

In many engineering and mathematics problems, sparsity is a popular topic [4]. In system identification and communication applications, the system may be in sparse nature [5] such as acoustic echo cancellation and network cancellation applications. Channel impulse response is frequently sparse due to high-speed data transmission, which will be dominated by a small number of high elements or taps [6],[7]. Many sparse LMS-type algorithms have been introduced lately to exploit sparsity. Gui et al. [8] applied the 10-LMS algorithm in order to estimate sparse channels to increase the accuracy of the estimate. In [9] a zero-attracting LMS (ZALMS) algorithm includes $l_{1}$-norm as a penalty term. In [10], a zero-point attraction projection uses 11 norm. In [11], $l_{p}$-norm is combined with $l_{1}$-norm. Another penalty term is $l_{0}$-norm was used [12] and its performance analysis is done [13]. A method in [14] is introducing sparse representations in overcomplete transforms, based on minimization of the $l_{0}$-norm.

In [15], the first two-dimensional adaptive filtering algorithm which can be applied as an adaptive line enhancer is presented. It is a direct extension of the one-dimensional (1D) LMS algorithm. Two-Dimensional (2D) adaptive filters are applied to the problems of image denoising as in [16]. The performance of the algorithms is improved by changing the step-size and updating the filter coefficients partially. In [15], a system identification application has been developed. It has linear adaptive filters, whose coefficients are refreshed in view of the standardized LMS calculation. In [16], another 2-D adaptive filtering application on equalization that employs the optimum (minimum mean-square-error (MSE) was proposed. A similar adaptive filter application algorithm has proposed in [17]. A different approach is in [18], two-dimensional adaptive filtering application is based on metaheuristic algorithms named artificial bee colony algorithm.

BM3D is one of the state-of-the art algorithms that have been used in image denoising which is based on the idea of sliding the image windows and searching the blocks includes a similarity with the processed one at that moment in three dimensional transform domain. The algorithm has two basic steps: The first one is about estimating the denoised image by hard thresholding and the second one is based on Wiener filtering where it is used for the original degraded image and the estimated version that handled from the initial step. [19].

Whatever remains of the paper is sorted out as following: Section 2 includes the proposed algorithm and the derivation of the convergence analysis. In Section 3, the data reuse patterns are discussed. In Section 4, simulations about image deconvolution are provided and discussed. At last, conclusions are drawn.

\section{Materials and methods}

Before deriving the proposed algorithm, we try to highlight the main role of the zero-attracting term in the one-dimensional 1D-ZALMS algorithm.

\subsection{Review of the 1D-ZALMS algorithm}

In the 1D-ZALMS algorithm, the cost function $J_{k}$ is defined by including the instantaneous squared error into the $l_{1}$-norm penalty of the weight vector, 


$$
J_{k}=\frac{1}{2} e_{k}^{2}+\gamma\left\|\mathbf{w}_{k}\right\|_{1}
$$

where $e_{k}$ is the instantaneous error given by $e_{k}=d_{k}-\boldsymbol{w}_{k} \boldsymbol{x}_{\boldsymbol{k}}$ $d_{k}$ is the desired response, $\gamma$ is a small positive parameter. $\mathbf{w}_{k}$ is the filter weight vector. The update equation of ZALMS filter is defined as:

$$
\mathbf{w}_{k+1}=\mathbf{w}_{k}-\mu \frac{\partial J_{k}}{\partial \mathbf{w}_{k}}=\mathbf{w}_{k}-\rho \operatorname{sgn}\left[\mathbf{w}_{k}\right]+\mu e_{k} \mathbf{x}_{k}
$$

where $\rho=\mu \gamma$. It controls the zero-attraction term. The sign function $\operatorname{sgn}($.$) is defined as:$

$$
\operatorname{sgn}(\tau)= \begin{cases}\frac{z}{|z|} & , z \neq 0 \\ 0 & , z=0\end{cases}
$$

The term $\rho \operatorname{sgn}\left[\mathbf{w}_{k}\right]$ forces zero attraction on zero or close-tozero coefficients. According to this; when the filter weight coefficient is positive, the value will decrease and vice versa.

\subsection{Extending to the $2 \mathrm{D}$ case}

The update equation of the 2D-ZALMS adaptive filter weight matrix can be given as:

$$
\mathbf{W}_{k+1}=\mathbf{W}_{k}-\mu \mathbf{G}_{k}
$$

Where $\mathbf{W}_{k}$ is the updated weight matrix of size $N \times N$. The estimate of the true 2D instantaneous gradient of $E\left\{e_{k}^{2}\right\}$, with respect to $\mathbf{W}_{k}$ is

$$
\mathbf{G}_{k}=\frac{\partial E\left\{e_{k}^{2}\right\}}{\partial \mathbf{W}_{k}}+\lambda\left\|\mathbf{W}_{k}\right\|_{1}
$$

$\mathbf{G}_{k}$ can be further expended to

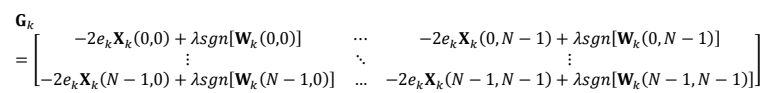

The ZALMS algorithm estimates the instantaneous gradient; [10] the gradient of the squared error of an iteration.

$$
\mathbf{G I}(r, c)=\frac{\partial e_{k}^{2}+\lambda \partial\left\|\mathbf{W}_{k}(r, c)\right\|}{\partial \mathbf{W}_{k}(r, c)}=-2 e_{k} \mathbf{X}_{k}(r, c)+\lambda s g n\left[\mathbf{w}_{k}(r, c)\right]
$$

where $\mathrm{r}$ and $\mathrm{c}$ denote the row and column indices, respectively. Substituting (7) in (4) and simplifying yields the weight update equation as:

$$
\begin{gathered}
\mathbf{W}_{k+1}(r, c)=\mathbf{W}_{k}(r, c)+\mu \mathbf{X}_{k}(l-r, m-c) d(l, m) \\
-\mu \mathbf{X}_{k}(-r,-c) y(r, c) \\
-\lambda \operatorname{sgn}\left[\mathbf{W}_{k}(r, c)\right]
\end{gathered}
$$

where the filter output is defined as:

$$
y(r, c)=\sum_{a=0}^{N-1} \sum_{b=0}^{N-1} \mathbf{w}_{k}(a, b) \mathbf{X}_{k}(l-a, m-b)
$$

The filter weights $\mathbf{w}_{v k}$ and the input data matrix $\mathbf{X}_{v k}$ can be reshaped into $1 \mathrm{D}$ form. During the $\mathrm{k}^{\text {th }}$ iteration, both column vectors $\mathbf{w}_{v k}$ and $\mathbf{X}_{v k}$ are respectively

$$
\begin{gathered}
\boldsymbol{w}_{v k}=\left[\begin{array}{c}
w_{k}(0,0) \\
\cdot \\
\cdot \\
w_{k}(0, N-1) \\
w_{k}(1,0) \\
\cdot \\
\cdot \\
w_{k}(N-1, N-1)
\end{array}\right] \\
\boldsymbol{x}_{v k}=\left[\begin{array}{c}
x_{k}(0,0) \\
\cdot \\
x_{k}(0, N-1) \\
x_{k}(1,0) \\
\cdot \\
\cdot \\
x_{k}(N-1, N-1)
\end{array}\right]
\end{gathered}
$$

According to these, (8) can be written as

$$
\begin{gathered}
\boldsymbol{w}_{v(k+1)}=\boldsymbol{w}_{v k}+\mu d(l, m) \boldsymbol{x}_{v k}-\mu \boldsymbol{x}_{v k} \boldsymbol{x}_{v k}{ }^{T} \boldsymbol{w}_{v k} \\
-\lambda \operatorname{sgn}\left[\boldsymbol{w}_{v k}\right]
\end{gathered}
$$

Hence, using (10) and (11) the 1D ZALMS can be used as a 2D-ZALMS algorithm in (12) and the update equation becomes:

$$
\begin{gathered}
\boldsymbol{w}_{v(k+1)}=\left(\mathbf{I}-\mu \boldsymbol{x}_{v k} \boldsymbol{x}_{v k}{ }^{T}\right) \boldsymbol{w}_{v k}+\mu d(l, m) \boldsymbol{x}_{v k} \\
-\lambda \operatorname{sgn}\left[\boldsymbol{w}_{v k}\right]
\end{gathered}
$$

where I is an $N \times N$ identity matrix. The step-size selection criteria of the proposed algorithm will be same with the standard LMS algorithm.

\subsection{The data reuse patterns}

The update equation of the ZALMS algorithm can be written in 2D form as:

$$
\begin{gathered}
\mathbf{w}_{n+1}\left(m_{1}, m_{2}\right)=\mathbf{w}_{n}\left(m_{1}, m_{2}\right)-\rho \operatorname{sgn}\left[\mathbf{w}_{n}\left(m_{1}, m_{2}\right)\right] \\
+\mu e(n) \mathbf{x}\left(n_{1}, n_{2}\right)
\end{gathered}
$$

Where $\mathbf{w}_{n}\left(m_{1}, m_{2}\right)$ is $N \times N$ weights matrix, $m_{1}=0,1, \ldots, N-$ 1 and $m_{2}=0,1, \ldots, N-1$. The filter weights and the input data can be reshaped into $1 \mathrm{D}$, respectively, by:

$$
\begin{aligned}
& \mathbf{w}_{n}\left(m_{1}, m_{2}\right)=\left[\begin{array}{c}
w_{n}(0,0) \\
\vdots \\
w_{n}(0, N-1) \\
w_{n}(1,0) \\
\vdots \\
w_{n}(N-1, N-1)
\end{array}\right] \\
& \mathbf{x}\left(n_{1}, n_{2}\right)=\left[\begin{array}{c}
x\left(n_{1}, n_{2}\right) \\
\vdots \\
x\left(n_{1}, n_{2}-N+1\right) \\
x\left(n_{1}-1,0\right) \\
\vdots \\
x\left(n_{1}-N+1, n_{2}-N+1\right)
\end{array}\right]
\end{aligned}
$$

For $2 \mathrm{D}$ applications, the update of the filter is done along the horizontal and vertical directions. The filtering of the image is implemented as follows: a subimage with the same size as of the filter itself is selected at each step by moving horizontally from left to right one pixel at a time till the last pixel in the respective row. Subsequently, the same process is repeated for each of the following row. This process will be repeated till the last pixel in the last row of the image. Results of the convolution of the filter 
and the subimage at each step will be calculated and recorded to obtain the filtered image.

Some possible ways of data reuse are shown in Figure 1. In the scheme shown in Figure 1(a), all the data should be used as shown. However, with the same considered mask size, another pattern as in Figure 1(b) with almost $63 \%$ of the pixels may be used. And in case of sparse images (where most of the pixels are zeros) [19] the performance of this pattern is very comparable to that in Figure 1(a) but with lower computation time.

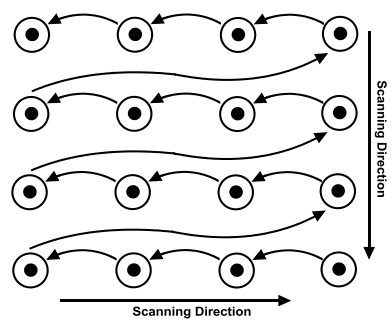

(a)

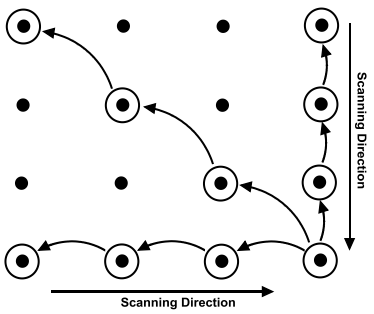

(b)
Figure 1: Configuration of data-reusing in 2-D, (a): Rectangular configuration, (b): Axial configuration.

\section{Experimental results}

\subsection{Subjective experiments}

In all of the conducted experiments in this study, we considered different 8 -bit $256 \times 256$ grayscale sparse and non-sparse images where the number of pixels with zero/near zero values is changing. Different noise were applied to the images, namely: additive white Gaussian noise (AWGN), salt \& pepper and speckle noise [20]. Comparisons for image denoising performance of the proposed 2D-ZALMS algorithm against BM3D and the conventional 2D-LMS algorithm were conducted. In the first experiment, Barbara and Lena images were degraded with additive white Gaussian noise AWGN with zero mean and 0.01 variance in Figure 2 and Figure 3, respectively. Parts (c) to (e) in aforementioned figures show the denoised images using the proposed 2D-ZALMS, BM3D and 2D-LMS algorithms, respectively. The quality of 2D-ZALMS based denoised image is clearly superior to the one obtained using the other two algortihms.

In order to test the performance of the proposed 2D-ZALMS algorithm under different noise types, the first experiment is repeated with the same parameters using two different noise. Second experiment uses speckle noise with zero mean and 0.01 variance (Figure 4 and Figure 5 ). Step size was chosen as $\mu=0.001$ for all algorithms. Figure 4 and 5 show that while BM3D algprithm is givining a blurred denoised images, the proposed 2D-ZALMS algorithm still performs the same as the 2D-LMS algorithm but with lower computation time.

In third experiement, Images were degraded by salt \& pepper noise with probability of 0.1 and $\mu=0.001$ for all algorithms (Figure 6 and Figure 7). Results are similar to the ones obtained in second experiment.

\subsection{Objective experiments}

To further emphasize the time consumption criteria of the proposed 2D-ZALMS and 2D-LMS, a comparison between the two algorithms is conducted under AWGN, speckle and salt\&pepper noise using different images with 2D-ZALMS using axial configuration. The results are shown in Table 1, Table 2 and Table 3, respectively. On average, the proposed 2D-ZALMS algorithm is $15.96,17.1$ and 17.45 times faster than the 2D LMS algorithm under the three noise types, respectively. This can be justified by the use of the axial configuration for the filter in 2DZALMS algorithm instead of the rectangular configuration which is used by the filter of the 2D LMS algorithm.

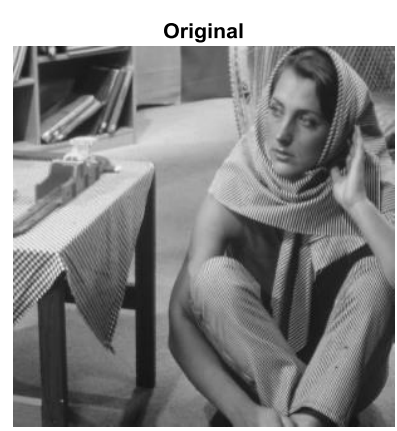

(a)

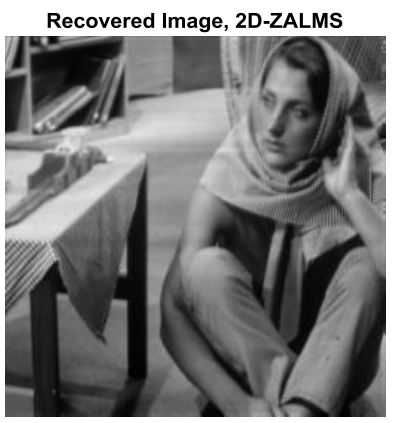

(c)

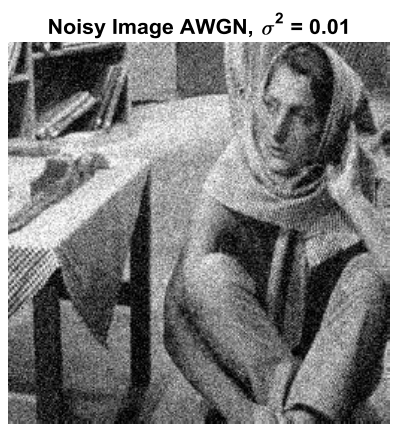

(b)

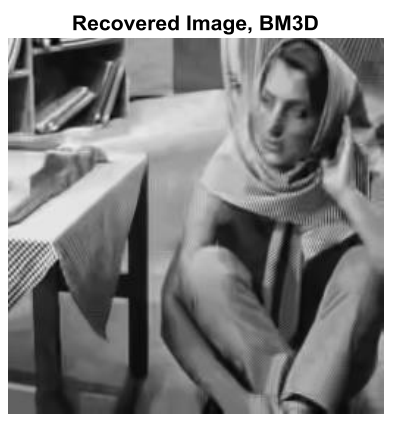

(d)

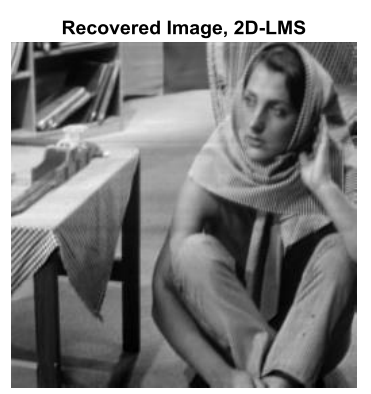

(e)

Figure 2(a): The original image "Barbara", (b): Noisy image (AWGN), denoising results using, (c): 2D-ZALMS algorithm, (d): BM3D algorithm, (e): 2D-LMS algorithm.

Table 1: Time consumption comparison in seconds between the 2D LMS and proposed 2D-ZALMS algorithms using different images under AWGN $\left(\sigma^{2}=0.01\right)$.

\begin{tabular}{|c|c|c|c|}
\hline $\begin{array}{c}\text { Image } \\
256 \times 256\end{array}$ & $\begin{array}{l}\text { 2D-ZALMS } \\
\mu=0.001 \\
\rho=10^{-4}, \varepsilon \\
=10 \\
\quad(\mathrm{sec})\end{array}$ & $\begin{array}{c}2 \text { D LMS } \\
\mu=0.001 \\
\quad(\mathrm{sec})\end{array}$ & $\begin{array}{l}\text { Gain } \\
\text { Factor }\end{array}$ \\
\hline Lena & 2.43 & 37.02 & 15.23 \\
\hline Moustache & 2.56 & 36.89 & 14.41 \\
\hline Rice & 2.59 & 38.82 & 14.98 \\
\hline \multicolumn{3}{|c|}{ Average Gain Factor } & 15.96 \\
\hline
\end{tabular}


Table 2: Time consumption comparison in seconds between the 2D LMS and proposed 2D-ZALMS algorithms using different images under Speckle noise $\left(\sigma^{2}=0.1\right)$.

\begin{tabular}{cccc}
\hline $\begin{array}{c}\text { Image } \\
256 \times 256\end{array}$ & $\begin{array}{c}\mu=0.001, \\
\rho=10^{-4}, \varepsilon \\
=10 \\
(\mathrm{sec})\end{array}$ & $\begin{array}{c}\text { 2D LMS } \\
(\mathrm{sec})\end{array}$ & $\begin{array}{c}\text { Gain } \\
\text { Factor }\end{array}$ \\
\hline Lena & 2.16 & 38.47 & 17.81 \\
Moustache & 2.13 & 36.54 & 17.16 \\
Rice & 2.12 & 36.16 & 17.06 \\
& Average Gain Factor & & 17.1 \\
\hline
\end{tabular}

Table 3: Time consumption comparison in seconds between the 2D-LMS and proposed 2D-ZALMS algorithms using different images under salt\&pepper noise $(\mathrm{Pr}=0.1)$.

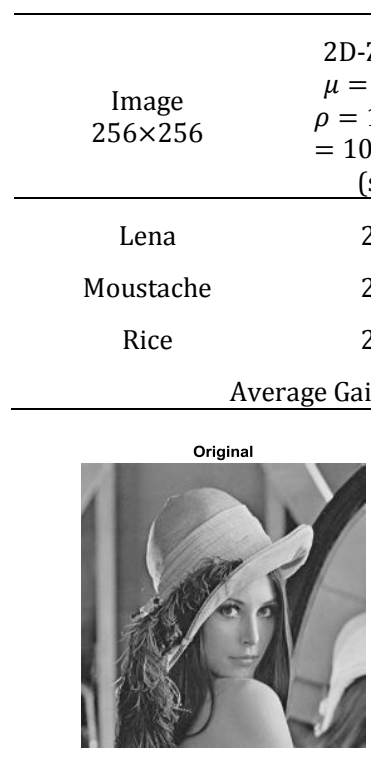

(a)

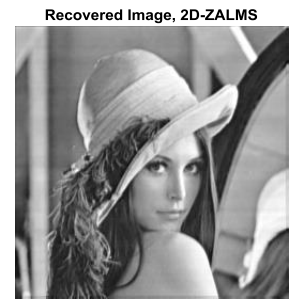

(c)

\section{D-ZALMS}

$\mu=0.001$,
$\rho=10^{-4}, \varepsilon$

(sec)

2.14

2.17

2.10

$=0.001$

(sec)

Gain

Factor

$39.40 \quad 18.41$

in Factor

17.47

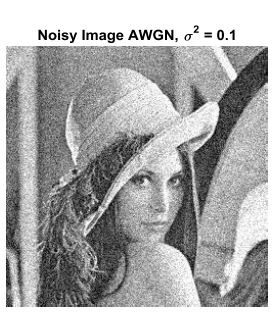

(b)

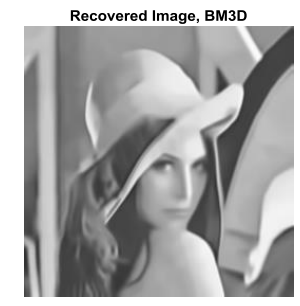

(d)

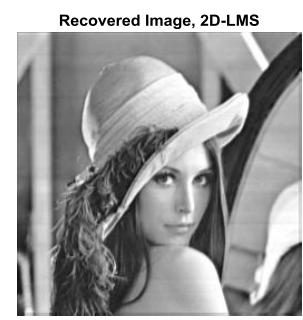

(e)

Figure 3(a): The original image "Lena", (b): Noisy image (AWGN), denoising results using, (c): 2D-ZALMS algorithm, (d): BM3D algorithm, (e): 2D-LMS algorithm.

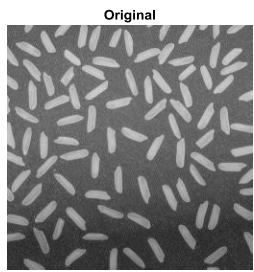

(a)

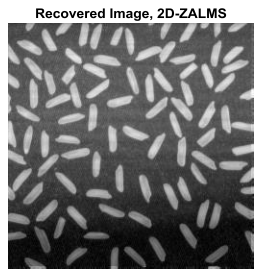

(c)

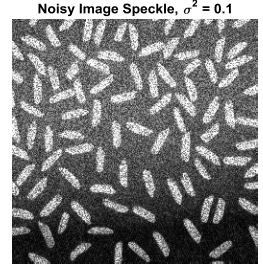

(b)

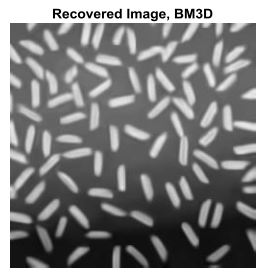

(d)

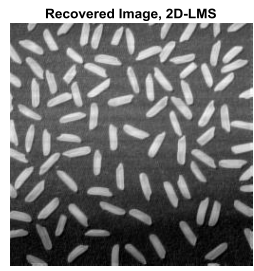

(e)
Figure 4(a): The original image "Rice", (b): Noisy image (Speckle), denoising results using, (c): 2D-ZALMS algorithm, (d): BM3D algorithm, (e): 2D-LMS algorithm.

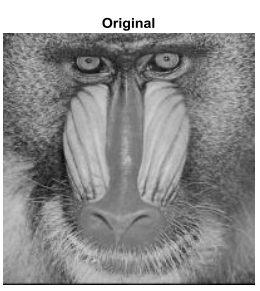

(a)

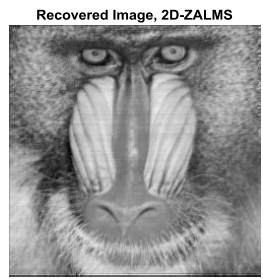

(c)

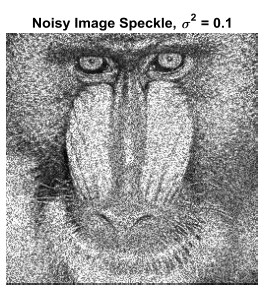

(b)

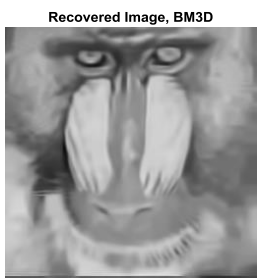

(d)

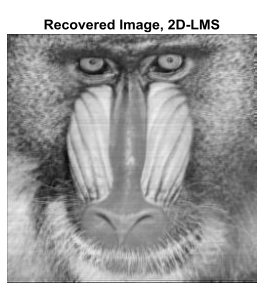

(e)

Figure 5(a): The original image "Baboon", (b): Noisy image (Speckle), denoising results using, (c): 2D-ZALMS algorithm, (d): BM3D algorithm, (e): 2D-LMS algorithm. 


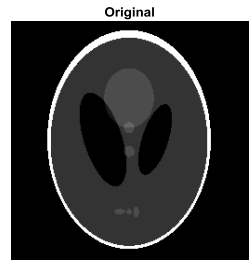

(a)

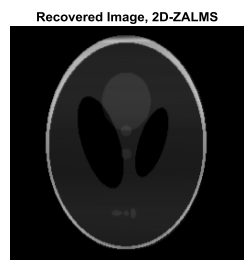

(c)

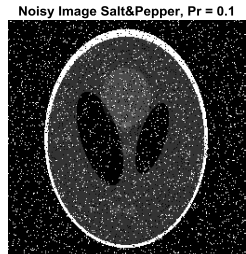

(b)

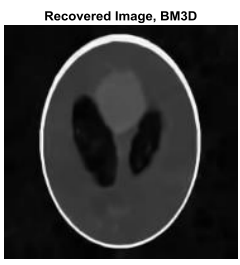

(d)

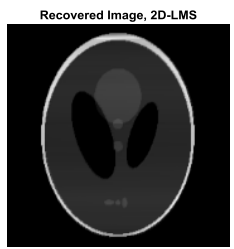

(e)

Figure 6(a): The original image "Phantom", (b): Noisy image (Salt\&Pepper), denoising results using, (c): 2D-ZALMS algorithm, (d): BM3D algorithm, (e): 2D-LMS algorithm.

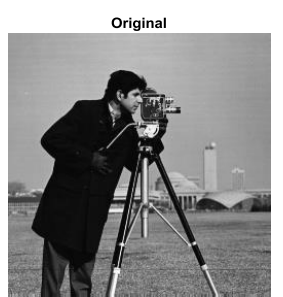

(a)

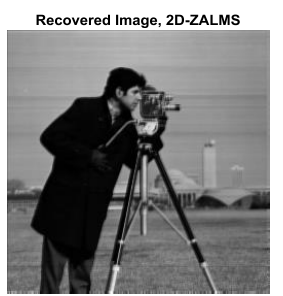

(c)

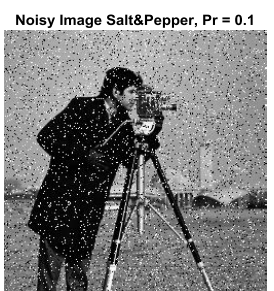

(b)

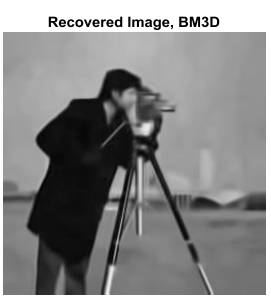

(d)

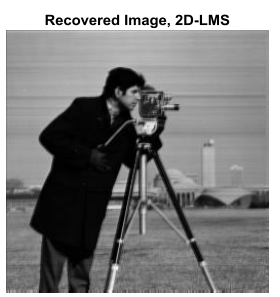

(e)

Figure 7(a): The original image "Cameraman", (b): Noisy image (Salt\&Pepper), denoising results using, (c): 2D-ZALMS algorithm (d) BM3D algorithm, (e): 2D-LMS algorithm.
Another objective test was conducted using the signal to noise ratio SNR, the peak signal to noise ratio PSNR and the SSIM.

The Structural Similarity (SSIM) Index quality assessment index is based on the computation of luminance, contrast and structural terms. The overall index is a multiplicative combination of these three terms. A simplified version of SSIM is given by

$$
\operatorname{SSIM}(x, y)=\frac{\left(2 \mu_{x} \mu_{y}+C_{1}\right)\left(2 \sigma_{x y}+C_{2}\right)}{\left(\mu_{x}^{2}+\mu_{y}^{2}+C_{1}\right)\left(\sigma_{x}^{2}+\sigma_{y}^{2}+C_{2}\right)}
$$

where $\mu_{x}, \mu_{y}, \sigma_{x}, \sigma_{x}$, and $\sigma_{x y}$ are the local means, standard deviations, and cross-covariance for images $\mathrm{x}$ and $\mathrm{y} . \mathrm{C}_{1}$ and $\mathrm{C}_{2}$ are very small constants which are included to avoid instability when the denominator is very close to zero.

PSNR and SNR are metrics for measuring the denoised/original image quality and usually is shown in the logarithmic decibel scale.

Given a denoised/recovered $N \times N$ 8-bit image x and its original version $y$. The formulae for SNR and PSNR metrics are given, respectively, as

$$
\begin{gathered}
\operatorname{SNR}(x, y)=\frac{\sum_{i=1}^{N} \sum_{j=1}^{N}[\mathrm{y}(i, j)]^{2}}{\sum_{i=1}^{N} \sum_{j=1}^{N}[x(i, j)-y(i, j)]^{2}} \\
\operatorname{PSNR}(x, y)=10 \log _{10}\left(\frac{255^{2}}{M S E}\right)
\end{gathered}
$$

where mean square error MSE is calculated by

$$
\operatorname{MSE}(x, y)=\frac{1}{N^{2}} \sum_{i=1}^{N} \sum_{j=1}^{N}[x(i, j)-y(i, j)]^{2}
$$

Comparisons between the 2D-LMS, BM3D and the proposed 2D-ZALMS algorithms for different images and AWGN with different noise variances are provided in Table 4 . Results on these tables indicate that with the increase in the noise level, the PSNR, SNR and SSIM values between the denoised image and the noisy image is decreasing. This is due to the increase in the MSE value which is inversely proportional to SNR and PSNR values. Generally, the proposed 2D-ZALMS is performing very close to the 2D LMS in terms of PSNR, SNR, SSIM and MSE values. As the higher PSNR value indicates that the algorithm performance is better than the others. However, it is clear from the table that, the PSNR, SNR and SSIM values for BM3D are relatively high compared to other algorithms.

\section{Discussion and conclusion}

A new two-dimensional algorithm presented in this work is introduced for improving the 2D-LMS algorithm performance. The new 2D zero-attracting least mean square (2D-ZALMS) adaptive filter is improving the performance by imposing a sparsity aware penalty term ( $l_{1}$-norm) into the cost function of the original 2D-LMS algorithm. Moreover, two data reuse configurations namely; rectangular and axial configurations were explained and utilized to boost the filtering process.

Images corrupted by different noise types with different parameters such as variance were used. Both algorithms showed comparable results both subjectively by human eye inspection and/or objectively using PSNR metric. 
Table 4: PSNR, SNR, SSIM and MSE comparisons between the 2D-LMS, BM3D and 2D-ZALMS algorithms under AWGN noise with different variance values. $\left(\mu=0.001, \rho=10^{-4}, \varepsilon=10\right)$.

\begin{tabular}{|c|c|c|c|c|c|c|c|c|c|c|c|c|c|}
\hline \multirow[b]{2}{*}{ Image } & \multirow{2}{*}{$\begin{array}{c}\text { Algorithm } \\
\text { Variance }\end{array}$} & \multicolumn{4}{|c|}{ 2D-ZALMS } & \multicolumn{4}{|c|}{ BM3D } & \multicolumn{4}{|c|}{ 2D-LMS } \\
\hline & & PSNR & SNR & SSIM & MSE & PSNR & SNR & SSIM & MSE & PSNR & SNR & SSIM & MSE \\
\hline \multirow{3}{*}{ Barbara } & 0.05 & 28.09 & 22.00 & 0.91 & 0.002 & 23.35 & 17.91 & 0.76 & 0.005 & 27.25 & 21.48 & 0.91 & 0.002 \\
\hline & 0.1 & 24.27 & 18.89 & 0.90 & 0.004 & 19.14 & 14.37 & 0.71 & 0.01 & 22.39 & 17.30 & 0.89 & 0.006 \\
\hline & 0.2 & 17.40 & 13.21 & 0.85 & 0.02 & 13.91 & 10.34 & 0.63 & 0.04 & 16.27 & 12.35 & 0.84 & 0.02 \\
\hline \multirow{4}{*}{ Baboon } & 0.05 & 22.85 & 18.87 & 0.74 & 0.005 & 20.34 & 16.70 & 0.47 & 0.0092 & 22.15 & 18.37 & 0.734 & 0.006 \\
\hline & 0.1 & 20.52 & 17.11 & 0.74 & 0.009 & 17.70 & 14.64 & 0.41 & 0.02 & 19.56 & 16.34 & 0.74 & 0.011 \\
\hline & 0.2 & 15.86 & 13.43 & 0.72 & 0.03 & 13.65 & 11.57 & 0.35 & 0.04 & 15.08 & 12.84 & 0.72 & 0.03 \\
\hline & 0.4 & 11.21 & 10.04 & 0.67 & 0.08 & 9.26 & 8.48 & 0.25 & 0.12 & 10.75 & 9.73 & 0.66 & 0.08 \\
\hline \multirow{4}{*}{ Lena } & 0.05 & 27.72 & 22.31 & 0.91 & 0.0017 & 23.39 & 18.48 & 0.79 & 0.0046 & 26.26 & 21.13 & 0.90 & 0.0024 \\
\hline & 0.1 & 23.26 & 18.53 & 0.89 & 0.0047 & 19.11 & 14.86 & 0.76 & 0.0123 & 21.58 & 17.10 & 0.89 & 0.007 \\
\hline & 0.2 & 16.74 & 13.17 & 0.85 & 0.02 & 13.92 & 10.83 & 0.70 & 0.04 & 15.78 & 12.43 & 0.84 & 0.03 \\
\hline & 0.4 & 11.14 & 9.14 & 0.76 & 0.08 & 8.70 & 7.28 & 0.56 & 0.14 & 10.60 & 8.80 & 0.75 & 0.09 \\
\hline \multirow{4}{*}{ Moustache } & 0.05 & 28.27 & 26.78 & 0.91 & 0.0015 & 27.11 & 25.81 & 0.98 & 0.0019 & 27.79 & 26.41 & 0.90 & 0.0017 \\
\hline & 0.1 & 24.36 & 23.20 & 0.91 & 0.0037 & 22.11 & 21.14 & 0.97 & 0.0061 & 23.44 & 22.39 & 0.90 & 0.0045 \\
\hline & 0.2 & 20.40 & 19.62 & 0.90 & 0.009 & 17.89 & 17.31 & 0.95 & 0.0162 & 19.64 & 18.96 & 0.89 & 0.011 \\
\hline & 0.4 & 18.86 & 18.25 & 0.90 & 0.013 & 14.71 & 14.34 & 0.91 & 0.0338 & 18.17 & 17.67 & 0.90 & 0.015 \\
\hline \multirow{3}{*}{ Rice } & 0.05 & 27.28 & 21.08 & 0.92 & 0.0019 & 22.63 & 17.24 & 0.69 & 0.0055 & 28.32 & 22.43 & 0.91 & 0.0015 \\
\hline & 0.1 & 26.32 & 20.76 & 0.92 & 0.0023 & 18.96 & 14.17 & 0.65 & 0.0127 & 24.64 & 19.38 & 0.90 & 0.0034 \\
\hline & 0.2 & 19.36 & 14.89 & 0.87 & 0.012 & 14.05 & 10.31 & 0.57 & 0.039 & 18.02 & 13.82 & 0.85 & 0.016 \\
\hline \multirow{3}{*}{ Cameraman } & 0.1 & 22.73 & 17.78 & 0.86 & 0.005 & 18.80 & 14.43 & 0.67 & 0.013 & 21.31 & 16.63 & 0.85 & 0.0074 \\
\hline & 0.2 & 16.76 & 13.02 & 0.82 & 0.02 & 13.70 & 10.52 & 0.60 & 0.043 & 15.77 & 12.27 & 0.81 & 0.027 \\
\hline & 0.4 & 11.15 & 9.016 & 0.74 & 0.08 & 8.66 & 7.15 & 0.51 & 0.13 & 10.59 & 8.65 & 0.73 & 0.09 \\
\hline
\end{tabular}

Still the results showed that the proposed 2D-ZALMS algorithm is faster than the 2D-LMS algorithm by a high gain factor under different noise types and parameters with image size $=256 \times 256, \mu=0.001, \rho=10^{-4}$, and $\varepsilon=10$. We compared the proposed algorithm with one of the state of the art algorithm BM3D as well. According to the experimental results, it has a blurry effect on the images. and the objective similarity metrics are higher than the 2D-ZALMS.

\section{References}

[1] Widrow B, Hoff M.E. "Associative storage and retrieval of digital information in networks of adaptive neurons". Biological Prototypes and Synthetic Systems, 160-160, 1962.

[2] Haykin S. Adaptive Filter Theory. $5^{\text {th }}$ ed. USA, Pearson, 2014.

[3] Hussain U, Kumar S. "Adaptive echo canceller using LMS algorithm". International Journal of Advance Engineering and Research Development, 2(8), 54-59, 2015.
[4] Wang X, Gu Y, Chen L. "Proof of convergence and performance analysis for sparse recovery via zero-point attracting projection". IEEE Transactions Signal Processing, 60(8), 4081-4093, 2012.

[5] Wright J, Ma Y, Mairal J, Sapiro G, Huang TS, Yan S. "Sparse representation for computer vision and pattern recognition". IEEE Proceedings, 98(6), 1031-1044, 2010.

[6] Czink N, Yin X, Ozcelik H, Herdin M, Bonek E, Fleury B. "Cluster characteristics in a MIMO indoor propagation environment". IEEE Transactions on Wireless Communications, 6 (4), 1465-1475, 2007.

[7] Vuokko L, Kolmonen VM, Salo J, Vainikainen P. "Measurement of large-scale cluster power characteristics for geometric channel models". IEEE Transactions on Antennas and Propagation, 55(11), 3361-3365, 2007.

[8] Gui G, Peng W, Adachi F. "Improved adaptive sparse channel estimation based on the least mean square algorithm". IEEE Wireless Communication and Networking Conference, Shanghai, China, 07-10 April 2013. 
[9] Chen Y, Gu Y, Hero AO. "Sparse LMS for system identification". IEEE International Conference on Acoustics, Speech and Signal Processing, Taipei, Taiwan, 4 April 2009.

[10] Wang X, Gu Y, Chen L. "Proof of Convergence and Performance Analysis for Sparse Recovery via Zero-Point Attracting Projection". IEEE Transactions on Signal Processing, 60(8), 4081-4093. 2012.

[11] Taheri 0, Vorobyov SA. "Sparse channel estimation with $\mathrm{l}_{\mathrm{p}}$-norm and reweighted $\mathrm{l}_{1}$-norm penalized least mean square". IEEE Conference on Acoustics Speech and Signal Processing (ICASSP), Prague, Czech Republic, 22-27 May 2011.

[12] Gu Y, Jin J, Mei S. "l $\mathrm{l}_{0}$-Norm constraint LMS algorithm for sparse system identification". IEEE Signal Processing Letters, 16(9), 774-777. 2009.

[13] Su G, Jin J, Gu Y, Wang J. "Performance analysis of 10-norm constraint least mean square algorithm". IEEE Transactions on Signal Processing, 60(5), 2223-2235, 2012. Mancera L, Portilla J. "lo-Norm-Based sparse representation through alternate projections". IEEE International Conference on Image Processing, Georgia, USA, 08-11 October 2006.
[14] Hadhoud MM, Thomas DW. "The two-dimensional adaptive LMS (TDLMS) algorithm". IEEE Transactions on Circuits and Systems , 35(5), 485-494, 1988.

[15] Abadi MSE, Nikbakht S. "Image denoising with twodimensional adaptive filter algorithms". Iranian Journal of Electrical \& Electronic Engineering, 7, 84-105. 2011.

[16] Zhang X, Jiang T, Li Y. “2D sparsity-information-aided least mean square algorithm for sparse image de-noising". Wireless Communications \& Signal Processing Conference, Yangzhou, China, 13-15 October 2016.

[17] Kockanat S, Karaboga N. "A novel 2D-ABC adaptive filter algorithm: A comparative study". Journal of Digital Signal Processing, 40, 140-153, 2015.

[18] Lebrun M. "An analysis and implementation of the BM3D image denoising method". Image Processing On Line, 2, 175-213, 2012

[19] Muneyasu M, Uemoto E, Hinamoto T. "A novel 2-D adaptive filter based on the 1-D RLS algorithm". IEEE International Symposium Circuits and Systems, Hong Kong, 12 June 1997.

[20] Yang J. Adaptive Filter Design for Sparse Signal Estimation. Ph.D. Dissertation, University of Minnesota, Minnesota, USA, 2011. 